\title{
(a)
}

\section{E-healthonderwijs is een nieuwe uitdaging voor de huisartsopleiding}

Elisa Houwink, Niels Chavannes, Anneke Kramer

Om goed voorbereid te zijn op de toekomst moeten aiossen zich ook in e-health verdiepen. Bij de huisartsopleiding ligt de nadruk echter meer op praktijkleren, waardoor nieuwe ontwikkelingen als e-health niet altijd voldoende aandacht krijgen. Aiossen moeten ook maar net een opleider treffen die zich met e-health bezighoudt. E-health verdient meer aandacht tijdens de opleiding, wat zowel de aios, de opleider als de docent ten goede zal komen.

De eerstelijnszorg heeft te maken met een snel veranderende context, zoals vergrijzing en meer complexe zorg, snelgroeiende medische kennis, veranderingen in de patiënt-zorgverlenerrelatie, een tekort aan zorgpersoneel, snelle technologische ontwikkelingen en sinds zo'n anderhalf jaar ook de COVID-19-pandemie..$^{1-3}$ Innovaties kunnen helpen bij het omgaan met deze veranderingen. E-health is er daar een van. Er is nog weinig ervaring met e-health in het medisch onderwijs en in de medisch onderwijskundige literatuur is er ook niet veel over te vinden. ${ }^{4}$ In dit artikel willen wij een aanzet geven voor een invulling van opleiding en nascholing in e-health. We gebruiken daarvoor onze kennis over en ervaring met e-health bij het National eHealth Living Lab (NeLL) en de LUMC Campus in Den Haag, en onze ervaring met medisch onderwijs, in het bijzonder de huisartsopleiding. We hebben daarbij gebruikgemaakt van relevante literatuur uit onder andere The European Journal of General Practice. ${ }^{4-6}$

\section{DEFINITIE EN FUNCTIES VAN E-HEALTH}

In het afgelopen decennium zijn verschillende definities van e-health voorgesteld, maar er bestaat nog geen consensus over. ${ }^{7}$ De meest genoemde definitie is die van Eysenbach: 'E-health verwijst naar gezondheidsdiensten en informatie die via internet en aanverwante technologieën wordt geleverd of kan worden verbeterd. In bredere zin kenmerkt de term niet alleen een technische ontwikkeling, maar ook een gemoedstoestand, een

Dit is een bewerkte vertaling van Houwink EJF, Kasteleyn MJ, Alpay L, Pearce C, Butler-Henderson K, Meijer E, et al. SERIES: eHealth in primary care. Part 3: eHealth education in primary care. Eur $\mathrm{J}$ Gen Pract 2020;2:108-18. Publicatie gebeurt met toestemming van de uitgever.
Figuur 1

Conceptualisering van e-health in de eerstelijnszorg volgens Shaw et al.4,9

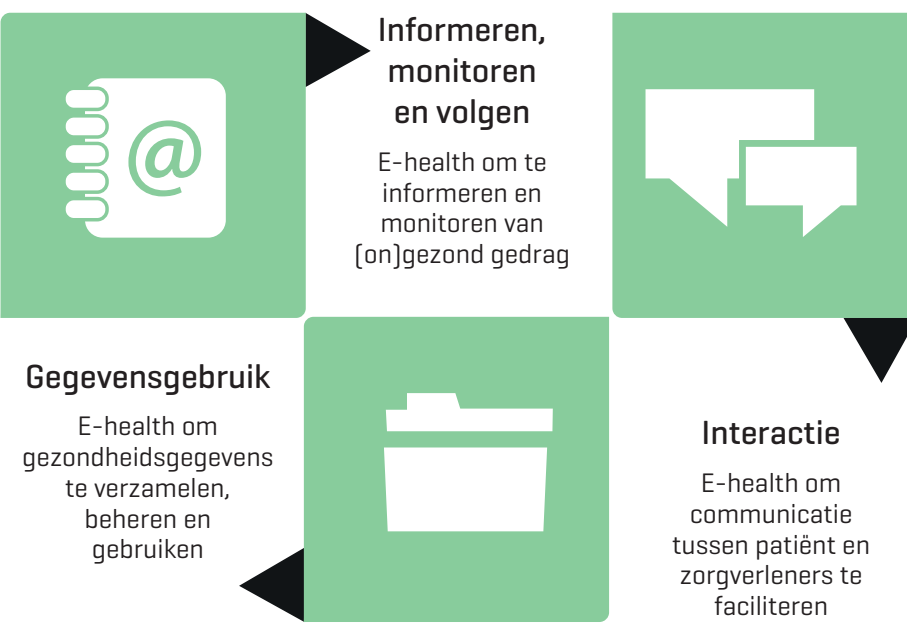

manier van denken, een houding en een inzet binnen een wereldwijd netwerk. E-health heeft tot doel de gezondheidszorg te verbeteren door gebruik te maken van informatie- en communicatietechnologie. ${ }^{8}$ Hoewel deze definitie informatief is, is een uitgebreidere beschrijving van e-health gerechtvaardigd. De conceptualisering van e-health van Shaw et al. onderscheidt 3 verschillende functies van e-health en beschrijft hoe deze kunnen bijdragen aan de eerstelijnszorg. ${ }^{9}$ De eerste functie is 'informeren, monitoren en volgen' en omvat het gebruik van e-healthtechnologieën in de dagelijkse praktijk om gezondheidsparameters te observeren en te onderzoeken. De tweede functie is 'interactie' en betreft het gebruik van e-health voor de communicatie tussen alle zorgdeelnemers (zorgverleners onderling en met patiënten). De laatste functie is 'gegevensgebruik', wat verwijst naar het verzamelen, beheren en gebruiken van gezondheids- en medische gegevensbronnen ten behoeve van medische besluitvorming en behandelingen [figuur 1].,9

\section{BELANG VAN E-HEALTH IN DE MEDISCHE OPLEIDING}

Binnen het medisch onderwijs wordt weliswaar erkend dat e-health een belangrijke rol speelt, maar tot nog toe wordt het nauwelijks tot niet geïncorporeerd. Een Australisch onderzoek liet zien dat zorgverleners de noodzakelijke competenties 


\section{DE KERN}

- E-health wordt binnen het medisch onderwijs weliswaar erkend, maar tot nog toe nauwelijks tot niet geïncorporeerd.

- Het is van belang om samen in de praktijk te oefenen met het toepassen van e-health, en hier tijdens terugkomdagen en leergesprekken tussen aios en opleider aandacht aan te besteden.

- Het CanMEDS-competentiemodel, de lijst aan digitale competenties die is samengesteld door het EU Standing Committee of European Doctors [CPME], en het model dat is gebaseerd op het Kern's stappenplan kunnen worden gebruikt om e-healthonderwijsprogramma's te ontwikkelen, evalueren en onderhouden.

voor een adequate toepassing van e-health in de dagelijkse praktijk ontberen. Dat komt omdat e-health geen plek heeft in het huidig medisch curriculum. In Europa bestaat een breed gedeelde behoefte om medisch studenten hierover te onderwijzen, zowel tijdens de geneeskundeopleiding als de vervolgopleiding. Er zijn wel initiatieven, maar die worden nog niet routinematig opgepakt. ${ }^{10,11}$

Om als gekwalificeerd medisch generalist te kunnen werken, moet de huisarts aan het eind van de opleiding kennis hebben van een breed scala aan aandoeningen en problemen. De mogelijkheden die e-health daarbij biedt lijken nog niet voldoende te worden gewaardeerd. Ook worden e-healthcompetenties niet altijd herkend, noch geaccrediteerd. Onlangs heeft het Standing Committee of European Doctors (CPME) zijn beleid geformuleerd rond digitale competenties van artsen. Het CPME vindt dat artsen (in opleiding) meer inzicht moeten hebben in digitale oplossingen en hun capaciteiten daarin kunnen vergroten. Artsen zouden ook zorg moeten dragen voor passend toezicht op klinische validatie van e-health, en tegelijkertijd geen overdreven vertrouwen moeten stellen in de technologie. ${ }^{12}$

\section{OPLEIDEN IN E-HEALTHVAARDIGHEDEN}

Toepassing van e-health in de praktijk vraagt niet alleen om vertrouwde vaardigheden in een nieuw jasje, zoals communiceren met de patiënt en samenwerken, maar ook om nieuwe vaardigheden, zoals het beoordelen van apps op kwaliteit en het gebruik van digitale data. E-health hoeft geen op zichzelf staand onderdeel te worden, want de impact zal groter zijn als ze wordt geïntegreerd in de huidige zorgpraktijk (blended care, face-to-face en online hulpverlening). Volgens het nieuwe raamplan voor de geneeskunde en het project Opleiden 2025 van de Federatie Medisch Specialisten moeten e-healthvaardigheden in de basis- en medische vervolgopleidingen worden opgenomen. ${ }^{13,14}$

De opleiding tot specialist huisartsgeneeskunde is beschreven in het Landelijk Opleidingsplan (LOP, 2016), dat is gebaseerd op het Competentieprofiel van de Huisarts. Dit competentieprofiel beoogt een toekomstgerichte en bestendige uitvoering van de huisartsenzorg. Het LOP omvat 10 thema's (zoals preventie en praktijkmanagement), met onder elk thema een set van Kenmerkende BeroepsActiviteiten (KBA's). Daarmee worden de afzonderlijke competenties van de huisarts vertaald naar de dagelijkse praktijk. ${ }^{15}$ Het LOP gaat niet uitgebreid in op e-healthvaardigheden, maar noemt ze bij de verschillende thema's (onder andere registreren en coderen binnen het huisartsinformatiesysteem, e-healthconsulten).

\section{WAT IS BELANGRIJK OM TE LEREN OVER E-HEALTH?}

Zorgverleners weten vaak niet welke e-healthtoepassingen beschikbaar zijn. Zijn de apps veilig, evidence-based en effectief? En hoe kun je deze apps implementeren in de dagelijkse praktijk? ${ }^{10}$ De volgende onderwerpen zijn volgens ons op dit moment van belang voor het e-healthonderwijs: kennis over en vaardigheid in e-healthtoepassingen in de praktijk, de invloed van e-health op de arts-patiëntrelatie, het gebruik van data, en het verzamelen en filteren van relevante digitale informatie. De casus laat zien welke rol e-health kan spelen in de zorg en het leergesprek tussen huisartsopleider en aios.

\section{CASUS MENEER JANSEN}

De aios ziet meneer Jansen [45 jaar] op het spreekuur. Meneer Jansen heeft moeilijk te behandelen hypercholesterolemie, omdat de statines vervelende bijwerkingen hebben. Hij heeft een positieve familieanamnese voor hart- en vaatziekten [zijn vader en broer overleden rond dezelfde leeftijd als gevolg van acute hartdood]. Zijn bloeddruk is $140 \mathrm{mmHg}$ systolisch en $80 \mathrm{mmHg}$ diastolisch. Door toenemende kortademigheid heeft hij de laatste tijd steeds meer moeite om trompet te spelen. De aios vermoedt dat er een relatie is tussen de positieve familieanamnese en de toenemende lichamelijke klachten, vanwege de leeftijd waarop de klachten bij meneer Jansen begonnen. In haar praktijk wordt e-health in dergelijke situaties veelvuldig toegepast, van klacht tot diagnose en behandeling. Ze bespreekt de casus met haar huisartsopleider.

De aios en haar opleider bespreken het gebruik van het elektronisch patiëntendossier [EPD]. Het EPD geeft een 'rode vlag' met als advies een verwijzing naar de cardioloog voor een CT-scan op coronair calcium en een genetische test via LEEFH.nl op familiaire hypercholesterolemie $[F H]$. De aios kijkt op huisartsengenetica.nl naar verwijsindicaties en stelt online verwijzing naar Cardiologie voor. Ze vraagt zich af hoe ze het beste de preventieve behandelopties met de patiënt kan bespreken en hoe ze een FH-test moet aanvragen. Ze weet dat evidencebased informatie online beschikbaar is via Thuisarts.nl en erfelijkheid.nl. Ze adviseert meneer Jansen om deze informatie over FH te lezen en om een week later de behandelopties te bespreken. Tijdens het vervolgconsult wordt besloten om een app in te zetten.

\section{Kennis en digitale vaardigheden}

Voor het toepassen van e-health is een basisniveau van digitale competentie nodig en eventueel toegang tot ICT-ondersteuning. ${ }^{16,17}$ Generatieverschillen hebben invloed op het gebruik van e-health: jongere zorgverleners en patiënten zijn bekender met digitale oplossingen dan oudere. Daarnaast is het vooral voor de zorgverlener van belang dat veiligheid, privacy en ethiek rond online ondersteuning in acht worden genomen. ${ }^{17}$ Van groot belang is ook dat e-health inclusiviteit bevordert. 


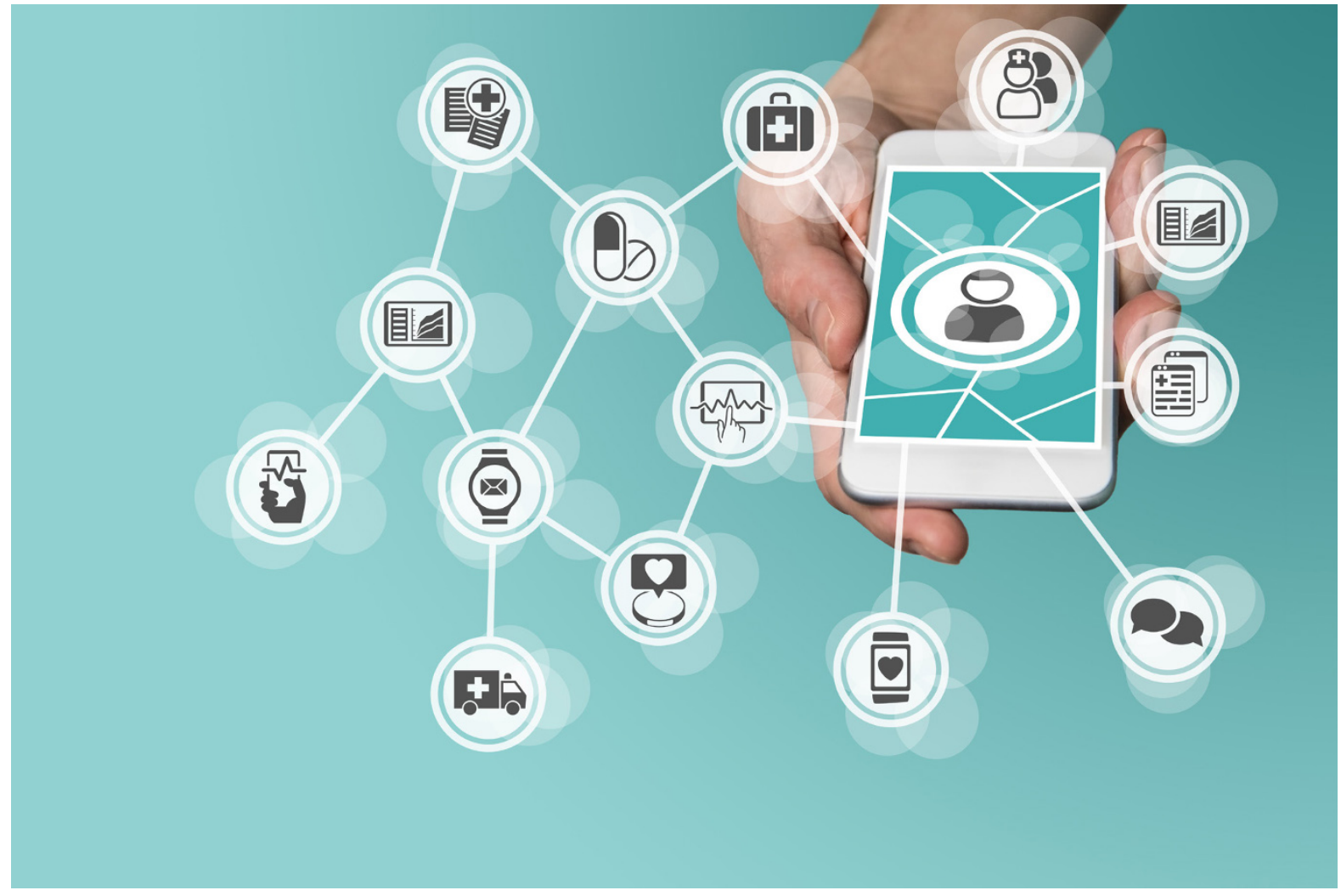

Inzicht in lacunes in de toepassing van e-health is een goed uitgangspunt om verder te leren.

Foto: Shutterstock

Mensen met minder digitale vaardigheden en een gebrek aan digitale voorzieningen verdienen specifieke aandacht om groei van gezondheidsverschillen te voorkomen. ${ }^{18}$ E-health kan helpen persoonsgerichte medische en preventieve zorg mogelijk te maken, zoals begeleiding bij het handhaven van een gezonde leefstijl en zelfmanagement van bijvoorbeeld COPD en diabetes.

\section{De arts-patiëntrelatie en communicatievaardigheden}

E-health kan de relatie tussen zorgverlener en patiënt beïnvloeden. Goed voorbereide patiënten weten soms meer dan hun huisarts, wat gevolgen heeft voor de rol van de laatste. De huisarts kan een laaggeletterde patiënt stimuleren informatie te zoeken op een specifieke site voor laaggeletterden, waardoor de patiënt zijn ziekte en behandeling mogelijk beter snapt. ${ }^{18}$ Ook dit heeft zijn weerslag op de interactie met de huisarts. ${ }^{19}$ Beslis- en ondersteuningsmodellen zullen de communicatie beinvloeden, bijvoorbeeld omdat patiënten beter in staat zijn om aan te geven wat ze over het advies of de voorgestelde behandeling denken. Zelfmanagement-apps geven inzicht in therapietrouw en maken gerichtere ondersteuning mogelijk. ${ }^{20}$ Huisartsen zijn naar onze mening in staat om deze vertaalslag te maken voor hun patiënten, zodat zo veel mogelijk mensen e-healthtoepassingen kunnen begrijpen en gebruiken. Wanneer e-health een integraal onderdeel wordt voor, tijdens en na een consult, moet de huisarts niet alleen kennis over e-health hebben, maar ook over passende communicatievaardigheden beschikken. Wat ons betreft moeten deze aspecten ook tijdens de huisartsopleiding en nascholingen voor huisartsen aan de orde komen.

\section{Het gebruik van gegevens}

Shaw omschrijft het gebruik van gegevens als het verzamelen en filteren van relevante digitale informatie, bijvoorbeeld gegevens uit het EPD en door de patiënt verzamelde gegevens in een app. Het gaat erom deze gegevensbronnen te verbinden en combineren, bijvoorbeeld in beslis- en ondersteuningsmodellen en websites. ${ }^{4}$ Zorgverleners kunnen deze gegevens gebruiken bij het vroeg diagnosticeren van ziekten en tijdig verwijzen en behandelen van patiënten. Artificiële intelligentie (AI) ondersteunt het gebruik van deze gegevens. AI is relatief nieuw in de gezondheidszorg, maar zal steeds meer invloed krijgen, bijvoorbeeld in de vorm van algoritmen. ${ }^{1,21,22}$

\section{E-HEALTHCOMPETENTIES INTEGREREN IN DE HUISARTS- OPLEIDING EN NASCHOLING}

De casus maakt duidelijk dat inzicht in lacunes in de toepassing van e-health een goed uitgangspunt is om verder te leren. De aios werd zich hiervan bewust omdat e-health in haar opleidingspraktijk wordt toegepast. De casus laat ook zien dat het nuttig is om praktijkervaringen met de huisartsopleider (of andere collega's binnen of buiten het zorgteam) te bespreken en om te oefenen. Tijdens de COVID-19-pandemie bleek hoe motiverend en leerzaam het is ervaringen met videobellen te delen. Mogelijk kunnen aiossen ook van elkaar leren hoe je e-health in de dagelijkse praktijk kunt inzetten door tijdens de terugkomdagen e-healthpraktijkervaringen uit te wisselen. Wanneer aiossen e-health zelf gaan toepassen kunnen hun opleiders het vervolgens van de aiossen leren. Daar moet tijdens terugkomdagen en leergesprekken dan wel ruimte voor worden gemaakt. 


\section{VERVOLG CASUS MENEER JANSEN}

De aios en meneer Jansen besluiten een app in te zetten om het serumcholesterol te verbeteren. De app is onderdeel van een groot onderzoek naar leefstijl en cholesterol. Via de app kunnen de gegevens worde gedeeld met de huisarts en andere zorgverleners in de praktijk. De daaropvolgende weken registreert hij zijn leefstijlgedrag en cholesterol. De aios gebruikt deze gegevens tijdens de volgende afspraak om de verdere behandeling te bespreken.

Voor formelere vormen van leren zijn voor de huisartsopleiding en de nascholing verschillende onderwijsactiviteiten geschikt: e-learnings, blended learning (e-learning in combinatie met fysieke scholing) en simulatieoefeningen met virtuele of echte oefenpatiënten. Ook coaching door een e-healthexpert of een stage in een omgeving waar e-health al veel wordt toegepast kan het leerproces ondersteunen. De aios leert dan van rolmodellen en de 'community of practice', zoals in de casus. Het CanMEDS-competentiemodel kan bij het ontwikkelen van een e-healthonderwijsprogramma worden gebruikt om e-healthleerdoelen te beschrijven in termen van rollen of competenties. Voor een voorbeeld verwijzen we naar het artikel waar deze beschouwing op is gebaseerd. Ook de lijst aan digitale competenties van het CPME kan als uitgangspunt dienen. ${ }^{12}$ Daarnaast kan Kern's 6-stappenmodel voor het ontwikkelen, evalueren en onderhouden van onderwijs ondersteuning bieden. Daarbij wordt eerst gekeken wat het probleem is waarvoor e-health een oplossing kan zijn. Stapsgewijs wordt nagegaan wat huisartsen (in opleiding) nodig hebben om de oplossing te implementeren. Door leerdoelen en leeractiviteiten te bepalen worden vervolgens uitvoering en evaluatie mogelijk [figuur 2]..$^{23-26}$

\section{TOT SLOT}

Met deze beschouwing willen we onderstrepen wat het belang is van onderwijs in e-health, zodat deze daadwerkelijk onderdeel van de praktijk gaat uitmaken. Hiervoor is nog wel een cultuurverandering nodig. Er zou een gevoel van urgentie moeten ontstaan om met e-health te gaan werken. Zo kunnen de actuele uitdagingen worden aangepakt, zoals de COVID-19pandemie, de toename in kennis over bijvoorbeeld (farmaco) genetica en de steeds complexer wordende samenwerking met patiënten, mantelzorgers en hulpverleners in het medische en psychosociale domein.

\section{LITERATUUR}

1. InHolland Hogeschool. Master Advanced Health Informatics Practice. www.inholland.nl/opleidingen/master-advancedhealth-informatics-practice/. Geraadpleegd op 30 maart 2021.

2. Groenhof TKJ, Asselbergs FW, Groenwold RHH, Grobbee DE, Visseren FLJ, Bots ML. The effect of computerized decision support systems on cardiovascular risk factors: a systematic review and meta-analysis. BMC Med Inform Decis Mak 2019;19:108.

3. Hollander JE, Carr BG. Virtually Perfect? Telemedicine for Covid-19. N Engl J Med 2020;382:1679-81.

De volledige literatuurlijst staat bij dit artikel op www.henw.org.

Houwink EJF, Chavannes NH, Kramer AWM. E-healthonderwijs is een nieuwe uitdaging voor de huisartsopleiding. Huisarts Wet 2021;64[7]:19-22. D0l:10.1007/s12445-021-1169-0.

Leids Universitair Medisch Centrum [LUMC], afdeling Public Health en Eerstelijnsgeneeskunde [PHEG], Leiden: dr. E.J.F. Houwink, huisarts, e.j.f.houwink@lumc.nl; prof. dr. N.H. Chavannes, huisarts; prof. dr. A.W.M. Kramer, huisarts.

Mogelijke belangenverstrengeling: niets aangegeven.

\section{Figuur 2}

Conceptueel model voor e-healthonderwijsontwikkeling, -evaluatie en -onderhoud, gebaseerd op Kern ${ }^{25-28}$

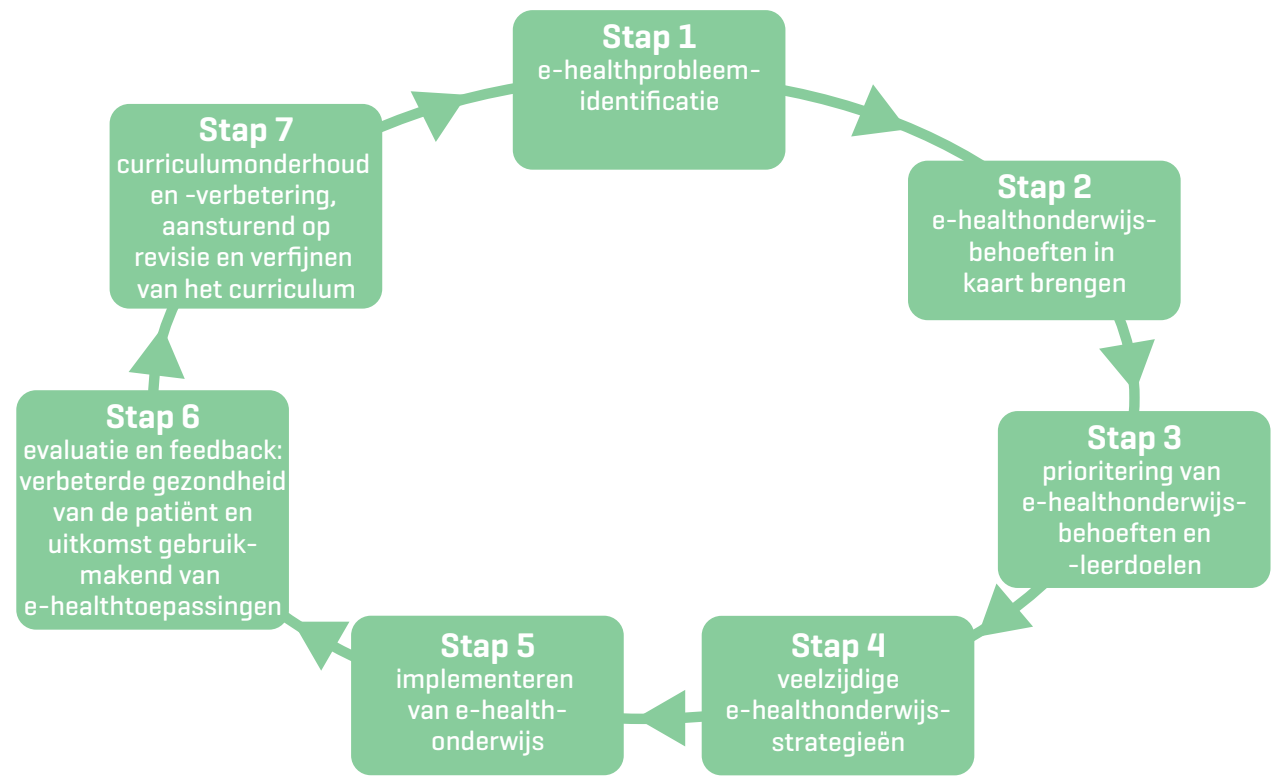

